\title{
ON BIVARIATE BERNSTEIN-CHLODOWSKY OPERATORS
}

\author{
H. GÜL İNCE İLARSLAN
}

Abstract. This work relates to bivariate Bernstein-Chlodowsky operator which is not a tensor product construction. We show that the operator preserves some properties of the original function, for example; function of modulus of continuity, Lipschitz constant, and a kind of monotony.

Mathematics subject classification (2010): 41A25, 41A35, 41A36.

Keywords and phrases: Bernstein-Chlodowsky operator, Lipschitz condition, modulus of continuity function, semi-additivity.

\section{REFERENCES}

[1] O. AgRatini, On a class of linear positive bivariate operators of King type, Stud. Univ. Babeş-Bolyai Math. 51 (2006), no. 4, 13-22.

[2] F. Altomare And M. CAmpiti, Korovkin type Approximation Theory and its Application, Walter de Gruyter Studies in Math 17, de Gruyter\&Co., Berlin 1994.

[3] G. A. Anastassiou And S. G. GAL, Approximation theory. Moduli of continuity and global smoothness preservation, Birkhäuser Boston, Inc., Boston, MA, 2000.

[4] B. M. BRown, D. Elliott AND D. F. PAGET, Lipschitz constants for the Bernstein polynomials of a Lipschitz continuous function, J. Approx. Theory, 49 (1987), 196-199.

[5] F. CAO, C. Ding And Z. XU, On multivariate Baskakov operator, J. Math. Anal. Appl., 307 (2005) no. 1, 274-291.

[6] W. Chen and Z. Ditzian, Mixed and directional derivatives, Proc. Amer. Math. Soc., 108 (1990) $178-185$.

[7] I. Chlodowsky, Sur le développement des fonctions définies dans un intervalle infini en séries de polynomes de M. S. Bernstein, Compositio Math., 4 (1937), 380-393.

[8] A. D. GADŽIEV, Theorems of the type of P. P. Korovkin's theorems, (Russian), Presented at the International Conference on the Theory of Approximation of Functions (Kaluga, 1975), Mat. Zametki., 20 (1976) no. 5, 781-786.

[9] E. IBIKLI, On approximation for functions of two variables on a triangular domain, Rocky Mountain J. Math., 35 (2005), no. 5, 1523-1531.

[10] H. KARSLi And V. GuPTA, Some approximation properties of q-Chlodowsky operators, Appl. Math. Comput., 195 (2008), no. 1, 220-229.

[11] M. K. KHAN AND M. A. PETERS, Lipschitz constants for some approximation operators of a Lipschitz continuous function, J. Approx. Theory., 59 (1989) no. 3, 307-315.

[12] Z. LI, Bernstein polynomials and modulus of continuity, J. Approx. Theory., 102 (2000) no. 1, 171174.

[13] A. P. Timan, The Theory of Approximation of the Functions of Real Variables, Phizmatgiz, 1960. 